\title{
Multi-sensor in situ observations to resolve the sub-mesoscale features in the stratified Gulf of Finland, Baltic Sea
}

\author{
Urmas Lips, Villu Kikas, Taavi Liblik, and Inga Lips \\ Marine Systems Institute at Tallinn University of Technology, Akadeemia Road 15a, 12618 Tallinn, Estonia \\ Correspondence to: Urmas Lips (urmas.lips@msi.ttu.ee)
}

Received: 26 January 2016 - Published in Ocean Sci. Discuss.: 4 February 2016

Revised: 8 April 2016 - Accepted: 14 May 2016 - Published: 27 May 2016

\begin{abstract}
High-resolution numerical modeling, remote sensing, and in situ data have revealed significant role of submesoscale features in shaping the distribution pattern of tracers in the ocean's upper layer. However, in situ measurements are difficult to conduct with the required resolution and coverage in time and space to resolve the sub-mesoscale, especially in such relatively shallow basins as the Gulf of Finland, where the typical baroclinic Rossby radius is $2-5 \mathrm{~km}$. To map the multi-scale spatiotemporal variability in the gulf, we initiated continuous measurements with autonomous devices, including a moored profiler and Ferrybox system, which were complemented by dedicated research-vesselbased surveys. The analysis of collected high-resolution data in the summers of 2009-2012 revealed pronounced variability at the sub-mesoscale in the presence of mesoscale upwelling/downwelling, fronts, and eddies. The horizontal wavenumber spectra of temperature variance in the surface layer had slopes close to -2 between the lateral scales from 10 to $0.5 \mathrm{~km}$. Similar tendency towards the -2 slopes of horizontal wavenumber spectra of temperature variance was found in the seasonal thermocline between the lateral scales from 10 to $1 \mathrm{~km}$. It suggests that the ageostrophic submesoscale processes could contribute considerably to the energy cascade in such a stratified sea basin. We showed that the intrusions of water with different salinity, which indicate the occurrence of a layered flow structure, could appear in the process of upwelling/downwelling development and relaxation in response to variable wind forcing. We suggest that the sub-mesoscale processes play a major role in feeding surface blooms in the conditions of coupled coastal upwelling and downwelling events in the Gulf of Finland.
\end{abstract}

\section{Introduction}

Essential contribution of mesoscale processes to the vertical exchanges of nutrients in the open ocean has been suggested and proved by a number of studies in the last 2 decades (e.g., McGillicuddy et al., 1998; Martin and Pondaven, 2003). These studies were motivated by the discrepancies between the direct measurements of vertical turbulent exchanges and indirect estimates of nutrient fluxes to support net primary production (Jenkins, 1988). Two conceptual views of additional nutrient supplies related to mesoscale eddies exist: (1) vertical exchanges due to the time evolution of eddies and (2) vertical pumping at small scales, i.e., within the submesoscale structures (Klein and Lapeyre, 2009). The latter hypothesis is supported by recent observations and modeling with increased spatial resolution suggesting that the submesoscale processes significantly contribute to the vertical exchange of water mass properties between the upper and deep ocean (Bouffard et al., 2012). Sub-mesoscale processes are characterized by order-one $(\mathrm{O}(1))$ Rossby and Richardson numbers (Thomas, 2008), large vertical velocity and vorticity fluctuations and large vertical buoyancy flux, resulting in considerable intermittency of oceanographic properties in the upper ocean (Capet et al., 2008).

Main physical forcing components for the non-tidal Baltic Sea system are the atmospheric forcing, exchange of heat energy and fresh water through the sea surface, and input of freshwater from rivers and the saltier North Sea water through the Danish Straits (Omstedt et al., 2004). It was identified already in the 1980s that the Baltic Sea has rich mesoscale variability with spatial scales $\mathrm{O}(10) \mathrm{km}$ through the whole water column (Aitsam et al., 1984) and evidence is increasing that remarkable changes occur in the system due to meso- and sub-mesoscale processes (e.g., Nausch et 
al., 2009; Lips et al., 2009). Recent results based on analysis of high-resolution in situ (Lips et al., 2011), numerical modeling (Laanemets et al., 2011) and remote sensing (Uiboupin et al., 2012) data from the Gulf of Finland showed that the sub-mesoscale features significantly shape the distribution pattern of tracers in this stratified basin. Among such features, the upwelling filaments and intra-thermocline intrusions with lateral scales less than the internal Rossby radius of deformation, which is about $2-5 \mathrm{~km}$ in the Gulf of Finland (Alenius et al., 2003), are named.

The layered structure of the major basins of the Baltic Sea, with the seasonal thermocline and the halocline situated at different depths - about 10-30 and 60-80 m, respectively, is a challenge to be accurately described by numerical models (Tuomi et al., 2012). In many cases, a proper validation of model results is difficult due to the absence of observational data with the required resolution and coverage in time and space. In order to fill this gap a number of autonomous devices, including moored profilers and Ferryboxes, and towed instruments are applied in the Gulf of Finland. According to high-resolution profiling at a fixed position in the Gulf of Finland, quasi-stationary stratification patterns of the thermocline occurred there at timescales of 4-15 days (Liblik and Lips, 2012) and the vertical dynamics of phytoplankton were largely defined by these patterns (Lips et al., 2011). Furthermore, temperature-salinity variability at the sub-mesoscale was significant during the transition periods between the quasi-stationary patterns (Liblik and Lips, 2012).

Coastal upwelling events are prominent mesoscale features in the Gulf of Finland (Uiboupin and Laanemets, 2009) leading to considerable vertical transport of nutrients into the euphotic layer (Laanemets et al., 2011; Lips et al., 2009) and influencing the phytoplankton growth and species composition (e.g., Lips and Lips, 2010). Analysis of Ferrybox data collected along the ferry line Tallinn-Helsinki in the central part of the Gulf of Finland revealed the occurrence of the two types of upwelling events (Kikas and Lips, 2015). In addition to the classical coastal upwelling with a strong upwelling front, the second type of upwelling event existed where a gradual decrease of surface layer temperature from the open sea towards the coast was observed. The latter type was characterized by a relatively high spatial variability at scales of a few to $10 \mathrm{~km}$, which as suggested by Kikas and Lips (2015) could be a sign of sub-mesoscale dynamics in the case of wind forcing not strong enough to produce an Ekman transport in the entire surface layer. This suggestion of higher sub-mesoscale activity associated with some types or phases of coastal upwelling has to be analyzed further. Such analysis based on combined Ferrybox, buoy profiler, and ScanFish data was one of the tasks of the present study.

According to the theory of quasi-geostrophic turbulence, the shape of the energy spectrum should follow the -3 slope in the logarithmic scale at the spatial scales below the mesoscale (Charney, 1971). It has been shown that if the spa- tial resolution of numerical models was increased the spectral slope converted to -2 rather than -3 (Capet et al., 2008) suggesting that sub-mesoscale processes play an important role in the energy cascade from larger to smaller scales. Still, it is a major challenge to map sub-mesoscale processes and phenomena by in situ observations. Due to the temporal and spatial scales to be resolved, the distinction between the temporal and spatial variability is difficult based on the highresolution 3-D surveys by a single technique, platform or device. We have applied in situ observations, using both autonomous devices and a research vessel, for mapping temporal variability in temperature, salinity and chlorophyll $a$ distribution patterns in the Gulf of Finland. Close to the Ferrybox line Tallinn-Helsinki, an autonomous profiler was deployed in the summers of 2009-2012. This data set allows us to estimate the temporal changes in the horizontal distribution patterns in the surface layer and vertical stratification (vertical temperature and salinity distribution) at a station close to the Ferrybox line simultaneously. In addition, ScanFish surveys were conducted in the area to reveal the spatial variability in the sub-surface layer.

The main aim of the present paper is to describe spatial and temporal variability at the mesoscale and sub-mesoscale, indicate the main sub-mesoscale features and their effects on the vertical stratification as well as chlorophyll $a$ dynamics under different forcing conditions by combining highresolution observational data (Ferrybox, buoy profiler, and ScanFish). We would like to demonstrate that multi-sensor in situ observations, initiated to meet the data needs in operational oceanography, are able to resolve the sub-mesoscale features and are a good basis for descriptive and statistical analysis of mesoscale and sub-mesoscale variability/features in the Gulf of Finland. The hypothesis that under certain mesoscale conditions, such as development and relaxation of coastal upwelling events in a stratified estuary, the submesoscale processes are more energetic than predicted by the theory of quasi-geostrophic turbulence in the ocean interior is tested.

\section{Material and methods}

\subsection{Measurement systems and data}

The data set analyzed in the present study was gathered using an observational network applied by the Marine Systems Institute at Tallinn University of Technology in the Gulf of Finland, Baltic Sea. It includes autonomous measurements and sampling on board a ferry traveling between Tallinn and Helsinki and autonomous measurements at a profiling buoy station close to the ferry route. Additionally, research-vesselbased measurements and sampling, as well as surveys using a towed undulating vehicle (ScanFish), are employed (Fig. 1).

The Ferrybox system records temperature $(T)$, salinity $(S)$, and chlorophyll $a$ (Chl $a$ ) fluorescence in the surface 


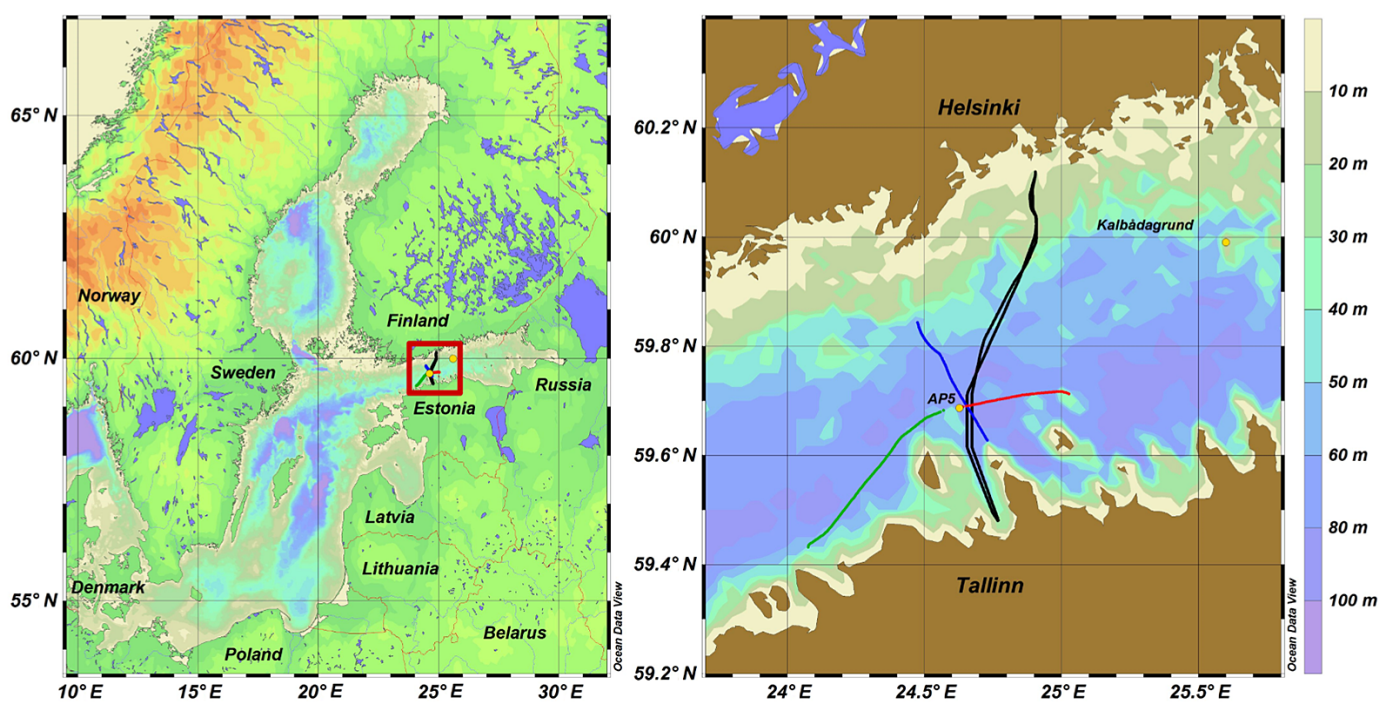

Figure 1. Map of the Baltic Sea (left panel) and the study area (right panel). Black lines indicate the Ferrybox route between Tallinn and Helsinki, blue line the ScanFish track on 22 July 2010, 2 August 2010, 4 July 2012, and 20 July 2012, green line the ScanFish track on 27 July 2010, and red line the ScanFish track on 31 July 2012. Yellow dots indicate the location of the buoy station AP5 and the Kalbadagrund meteorological station.

layer (water intake is approximately at $4 \mathrm{~m}$ depth) twice a day along the ferry route Tallinn-Helsinki (the system is described in detail by Kikas and Lips, 2015). The time resolution of measurements of $20 \mathrm{~s}$ corresponds to an average spatial resolution of $160 \mathrm{~m}$. For temperature measurements, a PT100 temperature sensor with a measuring range from -2 to $+40^{\circ} \mathrm{C}$ with an accuracy of $\pm 0.1 \%$ is used. The sensor is installed close to the water intake to diminish the effect of warming of water while flowing through the tubes onboard. For salinity measurements a FSI Excell thermosalinograph (temperature and conductivity meter) is used, and the data quality is checked by water sampling and analysis of samples by a high-precision salinometer Portasal 8410A (Guildline Instruments) 2-4 times a year. For Chl $a$ fluorescence and turbidity (turbidity data not presented here) measurements, a SCUFA (Self-Contained Underwater Fluorescence Apparatus) submersible fluorimeter (Turner Designs) with a flowthrough cap is used. An acid-washing cleaning system is applied to prevent biofouling and 11-17 water samples along the ferry route are collected once a week for laboratory analysis of Chl $a$ content to calibrate the fluorimeter data.

The autonomous profiler deployed in the summers of 2009-2012 at station AP5 (Fig. 1) recorded vertical profiles of temperature, salinity, and Chl $a$ fluorescence in the water layer from 2 to $50 \mathrm{~m}$ with a time resolution of $3 \mathrm{~h}$ and a vertical resolution of $10 \mathrm{~cm}$. The sensor set at the buoy profiler consisted of an OS316plus CTD probe (Idronaut S.r.l.) equipped with a Seapoint Chl $a$ fluorimeter. To avoid biofouling of sensors, the parking depth well below the euphotic layer depth and electrochemical antifouling system were applied. Ship-borne measurements and sampling close to the buoy profiler were arranged bi-weekly to check the quality of data (compare the vertical profiles from the buoy with those from the research vessel) and to calibrate the $\mathrm{Chl} a$ fluorimeter by laboratory analyses of $\mathrm{Chl} a$ content from the water samples.

The data set used also includes ScanFish surveys of temperature, salinity, and $\mathrm{Chl} a$ fluorescence conducted to map the horizontal distribution of $T, S$, and Chl $a$ in the water column from 2 to $45 \mathrm{~m}$ (see location of sections in Fig. 1). The average distance between the consecutive ScanFish cycles, including down- and upcast while the vessel was moving with a speed of 7 knots, was $600 \mathrm{~m}$. Data were recorded continuously (both down- and upcast are used) and the processed data were stored with a vertical resolution of $0.5 \mathrm{~m}$. The ScanFish sensor set consisted of a Neil Brown Mark III CTD probe and TriOS microFlu-chl-A fluorimeter. Shipborne CTD measurements and water sampling was conducted before and after the ScanFish surveys to control the quality of ScanFish data and calibrate the fluorimeter.

To calibrate the used (different) Chl $a$ sensors, the Chl $a$ concentration in the water samples was determined in the laboratory. Whatman GF/F glass fiber filters and extraction at room temperature in the dark with $96 \%$ ethanol for $24 \mathrm{~h}$ were used. The Chl $a$ content from the extract was measured spectrophotometrically (HELCOM, 1988) by Thermo Helios $\gamma$.

The data set from July-August 2009-2012 analyzed in the present study consists of 461 ferry crossings (TallinnHelsinki), $968 \mathrm{CTD}$ and $\mathrm{Chl}$ a profiles collected at station AP5, and 6 ScanFish surveys. 


\subsection{Calculations}

The results in the following sections are presented as graphs of pre-processed observational data and horizontal wavenumber spectra of temperature variance calculated from the Ferrybox and ScanFish measurements as well as the estimated characteristics of vertical stratification at station AP5. The use of spatial spectra of temperature (instead of density) was based on the assumptions that in summer in the surface and thermocline layer of the Gulf of Finland $(\mathrm{GoF})$, the water density is mainly controlled by temperature and it is measured by one sensor while density has to be estimated from the readings of two separate sensors. The following approaches are used in the calculations.

Horizontal wavenumber spectra of temperature variance were calculated for each ferry crossing between Tallinn and Helsinki assuming that the distance between the data points along the ferry route was constantly $160 \mathrm{~m}$. The areas close to the harbors, where the ferry speed varied, were excluded, and only the data along the ferry route between the latitudes 59.48 and $60.12^{\circ} \mathrm{N}$ were used. The mean spectra for a certain period with quasi-stationary variability were obtained by averaging of single spectra over this period. The spectral slopes between the spatial scales of 10 and $0.5 \mathrm{~km}$ were estimated. The overall variability was characterized by daily standard deviations of temperature along the ferry route.

Horizontal wavenumber spectra of temperature variance in the sub-surface layer were calculated using the data of ScanFish surveys. Since the distance between the consecutive profiles varies depending on the depth, the ScanFish data were first interpolated to the grid with a constant horizontal step of $300 \mathrm{~m}$, which corresponds to the average distance between the up- and downward casts. Then the individual spectra for every depth (with $0.5 \mathrm{~m}$ step) were calculated, and the mean spectra in $10 \mathrm{~m}$ thick water layers were obtained by averaging all spectra in those layers containing 21 individual spectra. The spectral slopes between the spatial scales of 10 and $1 \mathrm{~km}$ were estimated.

Vertical stratification was described by estimating the potential energy anomaly $P$ (Simpson and Bowers, 1981; Simpson et al., 1990) as

$$
P=\frac{1}{h} \int_{-h}^{0}\left(\rho_{\mathrm{A}}-\rho\right) g z \mathrm{~d} z, \quad \rho_{\mathrm{A}}=\frac{1}{h} \int_{-h}^{0} \rho \mathrm{d} z ;,
$$

where $\rho(z)$ is the density profile over the water column of depth $h$. The stratification parameter $P\left(\mathrm{~J} \mathrm{~m}^{-3}\right)$ is the work required to bring about the complete mixing of the water column under consideration. Similarly to Liblik and Lips (2012), the integration was conducted from the sea surface until $40 \mathrm{~m}$ depth. If the surface data were missing (upper $2 \mathrm{~m}$ where the buoy profiler did not measure), the uppermost available density value was extrapolated to the surface.

The intrusion index was calculated as a sum of negative salinity gradients $\left(\mathrm{g} \mathrm{kg}^{-1} \mathrm{~m}^{-1}\right)$ in the water layer from the sea surface to $40 \mathrm{~m}$ depth. Before calculations, the salinity profiles were smoothed by $2.5 \mathrm{~m}$ window. The idea behind the method comes from the fact that on the background of vertical salinity gradient with a fresher surface layer and more saline deep layer, lateral salinity gradients exist in the study area. In general, fresher water originates from the east (the Neva River and other larger rivers in the GoF) while more saline water originates from the Baltic proper. This general lateral salinity gradient could be enhanced locally as a result of meso- and sub-mesoscale dynamics. If the water layers with a thickness of a few to $10 \mathrm{~m}$ move in different directions, vertical salinity inversions could be generated in the water column where the vertical density gradient is mostly maintained by the temperature distribution. Thus, high values of intrusion index indicate the occurrence of layered flow structures.

The Chl $a$ fluorescence data acquired with different sensors attached to the Ferrybox system, buoy profiler, and ScanFish were converted into Chl $a$ content values using equations of linear regression between the fluorescence readings and results of laboratory analyses of water samples. The conversation equation of Chl $a=2.47 \times F\left(r^{2}=0.41\right.$, $p<0.05)$ was used for the buoy profiler fluorescence data analyzed in this paper to convert fluorescence $(F$; in arbitrary units) into Chl $a$ content in $\mathrm{mg} \mathrm{m}^{-3}$. Interpretation of Ferrybox fluorescence data was sometimes difficult due to some problems with biofouling. In the present study, we used only data from July 2010 when the found regression line had the following parameters: Chl $a=2.34 \times F-2.41$ $\left(r^{2}=0.77, p<0.05\right)$ and from summer 2012 by applying the following regression line equation: $\mathrm{Chl} a=1.06 \times F-4.11$ $\left(r^{2}=0.80, p<0.05\right)$. Data only from evening crossings were used to diminish the fluorescence quenching effect.

\section{Results}

\subsection{Forcing and general features}

The study period in July-August of 2009-2012 was characterized by distinct inter-annual differences in wind conditions and distribution patterns of temperature and salinity in the central part of the Gulf of Finland. Based on HIRLAM (High-Resolution Limited Area Model) wind data, the average wind speed in July-August 2009-2012 in the GoF area was $6.0 \mathrm{~m} \mathrm{~s}^{-1}$, and the prevailing wind direction was from the south-southeast with an average velocity of the airflow of $1.4 \mathrm{~m} \mathrm{~s}^{-1}$. While the winds from the southwest prevailed in July-August 2009 and 2012 (average direction from 217 and $214^{\circ}$, respectively), the dominating wind direction was from the southeast in 2010 and 2011 (average direction from 160 and $122^{\circ}$, respectively). Both in 2010 and in 2011 the monthly average wind direction differed between the 2 analyzed months being from $192^{\circ}$ in July to $115^{\circ}$ in August 2010 and from $73^{\circ}$ in July to $177^{\circ}$ in August 2011. 

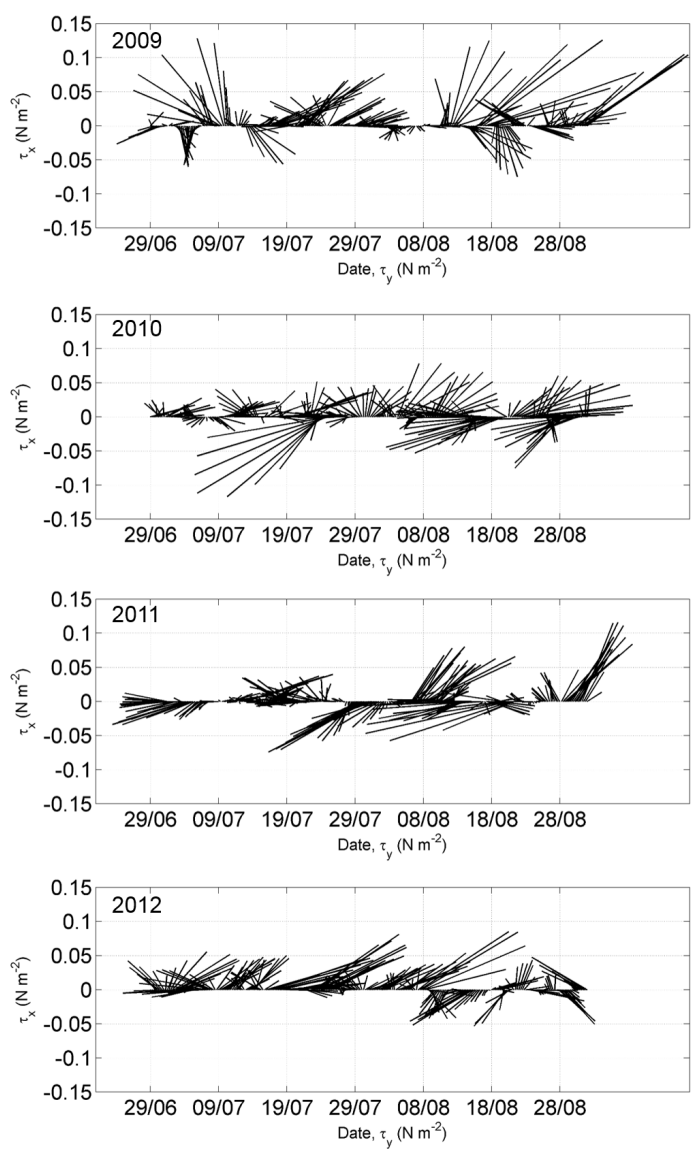

Figure 2. Temporal changes in wind stress during the study period of 29 June-31 August in 2009-2012 based on $3 \mathrm{~h}$ average wind measured at the Kalbadagrund meteorological station (Finnish Meteorological Institute) and shown as series of wind stress vectors with a time step of $6 \mathrm{~h}$ smoothed using $24 \mathrm{~h}$ moving average.

On the synoptic scale (several days - a couple of weeks), mostly westerly wind pulses occurred in 2009 except for a period in the first half of July with a relatively strong wind pulse from the south-southeast (see time series of wind stress vectors in Fig. 2). In 2010, moderate winds from the southwest were prevailing in the first half of July while several wind pulses from the east, northeast and south occurred during the rest of the study period. Typical for 2011 was a consecutive appearance of relatively strong wind pulses from southwest and east-northeast. In 2012, westerly winds clearly prevailed with only two short periods when the wind pulses from the east (early July) and northeast (second half of August) occurred.

In general, as described by Kikas and Lips (2015) based on Ferrybox data, the surface layer temperature was clearly higher in 2010 and 2011 than in 2009 and 2012. The surface layer salinity was the highest at the beginning of the study period in 2011; the less saline water occupied the central gulf in 2009 and the second half of summer in 2010 and 2011 while the surface layer salinity stayed relatively high in JulyAugust 2012.

Based on the combined figures of horizontal and vertical distributions of temperature and salinity in July-August 2009 (Fig. 3a and b), the following characteristic features could be identified. In the first half of July, an upwelling event developed near the southern coast resulting in large variations of temperature $\left(7.8-17.8^{\circ} \mathrm{C}\right.$ ) and salinity $\left(4.2-6.1 \mathrm{~g} \mathrm{~kg}^{-1}\right.$ ) across the gulf. Deepening of the thermocline occurred after the upwelling relaxation in the southern part of the gulf. A shallow and warm upper layer (temperature between 17.3 and $20.4^{\circ} \mathrm{C}$ ) with very low variations of salinity across the gulf (between 4.6 and $5.0 \mathrm{~g} \mathrm{~kg}^{-1}$ ) appeared in the study area due to a period of weak winds in the first half of August. Upwelling near the southern coast occurred in the second half of August with increased across-gulf variability of temperature (from 12.9 to $17.7^{\circ} \mathrm{C}$ ) and salinity $\left(4.7-5.6 \mathrm{~g} \mathrm{~kg}^{-1}\right.$ ).

At the beginning of the study period in 2010 , when mainly weak or variable moderate winds prevailed, the variations of temperature (mostly being between 20 and $22^{\circ} \mathrm{C}$ ) and salinity in the surface layer were very low across the gulf (Fig. 3c and d). This calm period was followed by a relatively weak upwelling event off the northern coast and deepening of the thermocline from $10 \mathrm{~m}$ to $15 \mathrm{~m}$ in the southern part. A strong upwelling event near the southern coast with the high spatial variability of temperature (varying between 11.1 and $21.6^{\circ} \mathrm{C}$ ) and salinity (varying between 4.0 and $6.3 \mathrm{~g} \mathrm{~kg}^{-1}$ ) across the gulf occurred in late July. The seasonal thermocline had a much shallower position in 2010 (for the period with available data until early August) than in 2009.

Study period in July-August 2011 started with an upwelling event near the southern coast with the surface layer temperature varying across the gulf from 12.8 to $20.6^{\circ} \mathrm{C}$ and salinity varying from 5.1 to $6.5 \mathrm{~g} \mathrm{~kg}^{-1}$ (Fig. $3 \mathrm{e}$ and f). During the next extensive upwelling event in late July-early August off the southern coast, high variability of the surface layer temperature (varying between 13.5 and $21.4^{\circ} \mathrm{C}$ ), and salinity (varying between 4.4 and $6.4 \mathrm{~g} \mathrm{~kg}^{-1}$ ) across the gulf was observed. Relaxation of the latter event was accompanied by a moderate deepening of the thermocline in the southern part of the gulf. Strong winds from variable directions in the second half of August caused strong vertical mixing and downwelling with a drastic deepening of the seasonal thermocline to $45 \mathrm{~m}$ depth in the southern part of the gulf.

The first half of July 2012 was characterized by relatively low spatial variability of temperature and salinity in the surface layer of the study area (Fig. $3 g$ and h). An upwelling event occurred near the northern coast at the end of July, creating a temperature difference across the gulf from 10.3 to $17.2^{\circ} \mathrm{C}$, and accompanied by the deepening of the seasonal thermocline in the southern part (to $45 \mathrm{~m}$ ). After a short period with low variability, the second upwelling event appeared near the northern coast while the surface layer temperature stayed quite high in the rest of the study transect (up to $20^{\circ} \mathrm{C}$ ). In the period between the two upwelling events, 

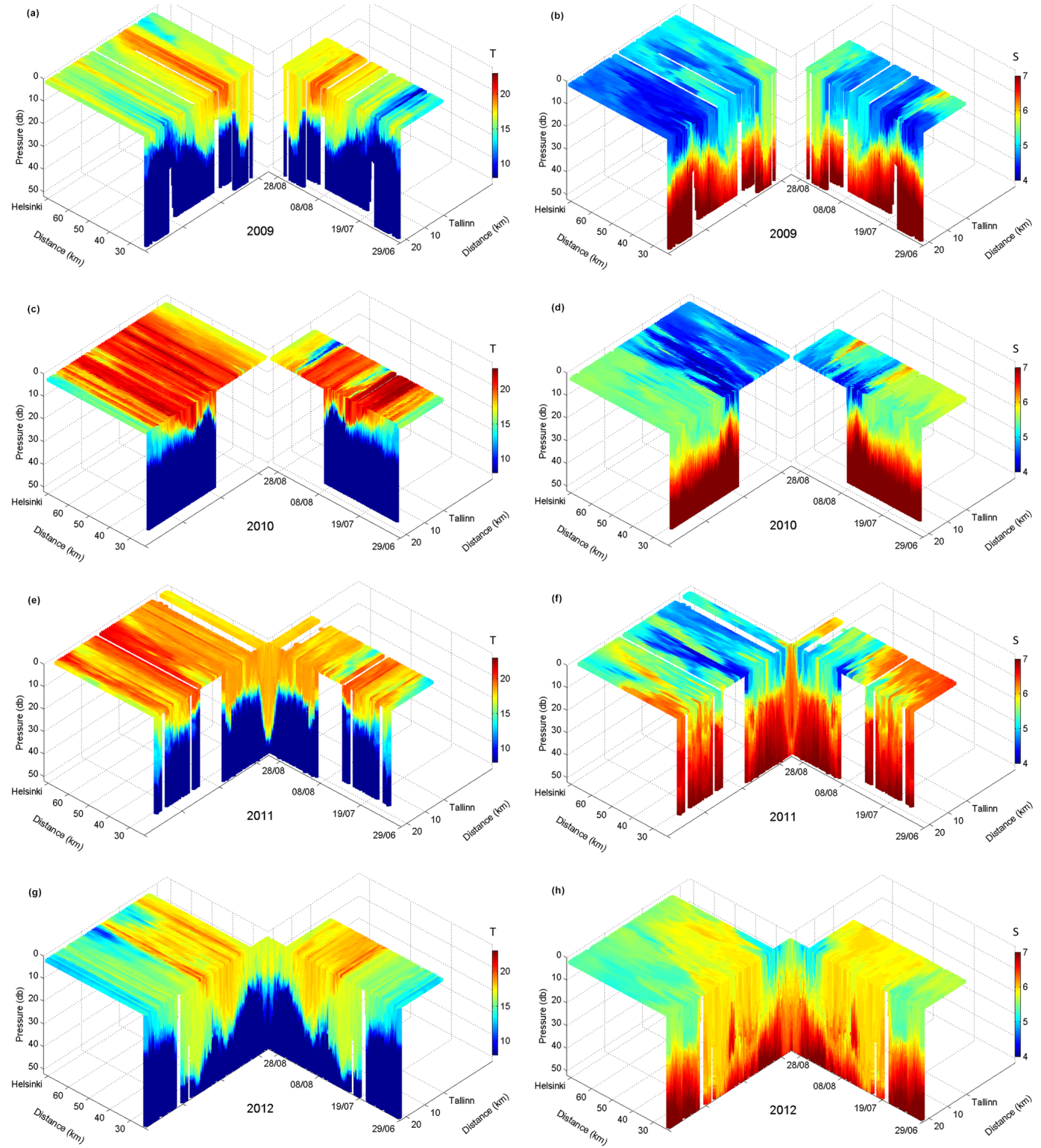

Figure 3. Temporal changes in horizontal and vertical distributions of temperature $\left({ }^{\circ} \mathrm{C}\right)$ and salinity $\left(\mathrm{g} \mathrm{kg}^{-1}\right)$ in the Gulf of Finland measured by the Ferrybox system between Tallinn and Helsinki and the autonomous buoy profiler at station AP5 from 29 June to 31 August in 2009 (a, b, respectively), 2010 (c, d), 2011 (e, f), and $2012(\mathbf{g , h})$. The Ferrybox data are split into two parts at the position of the buoy profiler AP5. The $x$ axis shows the distance along the ferry route from a starting point off Tallinn harbor at the latitude of $59.48^{\circ} \mathrm{N}$.

strong intrusions of more saline water were observed in the subsurface layer at the buoy station. The position of the seasonal thermocline in the southern part of the gulf was the deepest in 2012 among the analyzed years.

\subsection{Lateral variability of temperature in the surface layer}

Overall horizontal variability of temperature characterized as the standard deviation of temperature along the ferry route varied in quite large ranges in time, from 0.2 to $3.7^{\circ} \mathrm{C}$
(Fig. 4). High values of standard deviation of temperature in the surface layer were related to the observed coastal upwelling events and, as a rule, the upwelling events near the southern coast resulted in larger spatial variations of temperature than those near the northern coast. During the upwelling event in August 2010, the standard deviation of temperature was as high as $3.7^{\circ} \mathrm{C}$ while during the other upwelling events within the study period in July-August 2009_ 2012, the values of standard deviation of temperature did not exceed $2.5^{\circ} \mathrm{C}$. Despite the high temporal variability of standard deviations of temperature calculated based on data from 

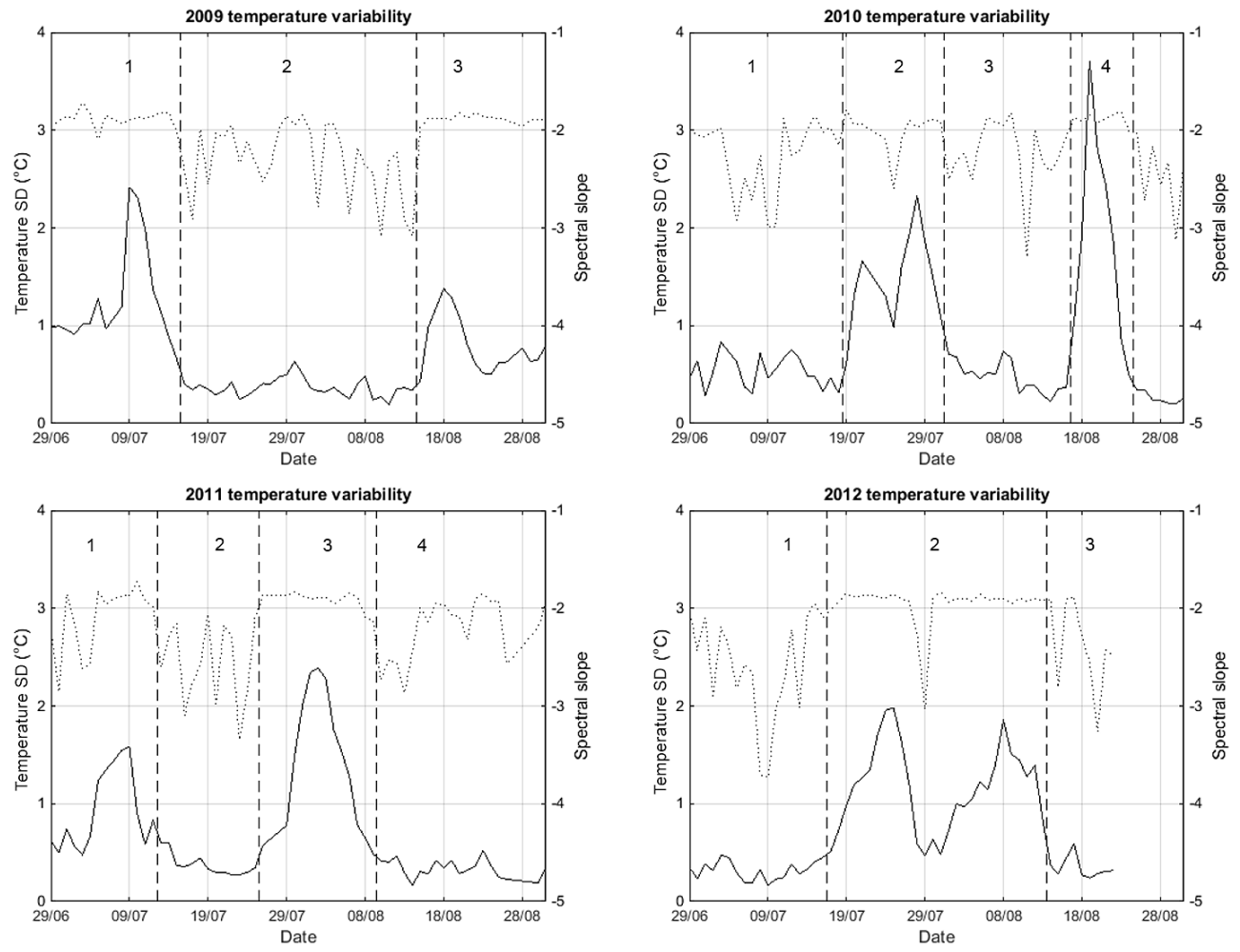

Figure 4. Statistical characteristics of the temperature variability in the surface layer of the Gulf of Finland along the ferry route TallinnHelsinki from 29 June to 31 August in 2009, 2010, 2011, and 2012. Standard deviations of temperature are shown as solid lines and spectral slopes of temperature variance between the horizontal scales of 10 and $0.5 \mathrm{~km}$ as dotted lines. The vertical dashed lines denote the borders between the selected characteristic periods with similar variability patterns (numbers of periods are shown in the upper part of the panels).

single crossings, the average values of standard deviations for the studied 4 years did not differ much; a minimum of $0.71^{\circ} \mathrm{C}$ was found in 2009 and a maximum of $0.83^{\circ} \mathrm{C}$ in 2010 (Table 1).

The calculated horizontal wavenumber spectra of temperature variance had also relatively large variability if to compare the spectra estimated based on data from single crossings. The spectral slope between the lateral scales of 10 and $0.5 \mathrm{~km}$ varied between -1.8 and -3.7 (in logarithmic scales). Note that the spectral curves were approximately linear (Fig. 5) between the scales of $15-20 \mathrm{~km}$ (the latter corresponds to a horizontal wavenumber of $0.05 \mathrm{~km}^{-1}$ or in a logarithmic scale -1.3 in Fig. 5) and $0.5 \mathrm{~km}$ (corresponds to wavenumber of $2 \mathrm{~km}^{-1}$ or in logarithmic scale 0.3 in Fig. 5); thus, linear approximation of their slopes is feasible. Within the periods of the high spatial variability of temperature, mostly related to upwelling events affecting the distribution of temperature in the surface layer of the Gulf of Finland, the estimated slopes were between -1.8 and -2 . When the spatial variability of temperature was low in the surface layer, the slopes varied mostly between -2 and -3 (Fig. 4). At the same time, the average spectra for the entire period under consideration in the studied years were quite close to each other (Fig. 5, bold lines) and the spectral slopes on average were close to -2 (from -2.1 to -2.2 ; see also Table 1 ).

Based on the presented lateral variability of temperature, some distinct periods when the standard deviation of temperature was high and spectral slope was close to -2 can be distinguished. We selected 3-4 periods with the almost quasi-stationary character of variability in each year to quantitatively describe the character of variability within these periods; the periods are marked in the Fig. 4 by dashed lines.

In 2009, two periods of high spatial variability caused by coastal upwelling events existed (periods 1 and 3 marked in Fig. 4). During both periods, the spectral lines had a higher position, and their slopes were shallower than the average for the entire study period in 2009 (see Fig. 5 and Table 1). In 2010, two periods, which were also associated with the upwelling events (periods 2 and 4; see Fig. 4), had much higher spatial variability, and the spectral slopes were shallower than the average in 2010. All time intervals comprising upwelling events in 2011 (periods 1 and 3; see Fig. 4) and 2012 (period 2; see Fig. 4) were also characterized by a higher position and shallower slope of spectral lines than the lines representing the average for July-August 2011 and 2012. The noticed divergence of spectral slopes from the high-variability and low-variability periods resulted in a 

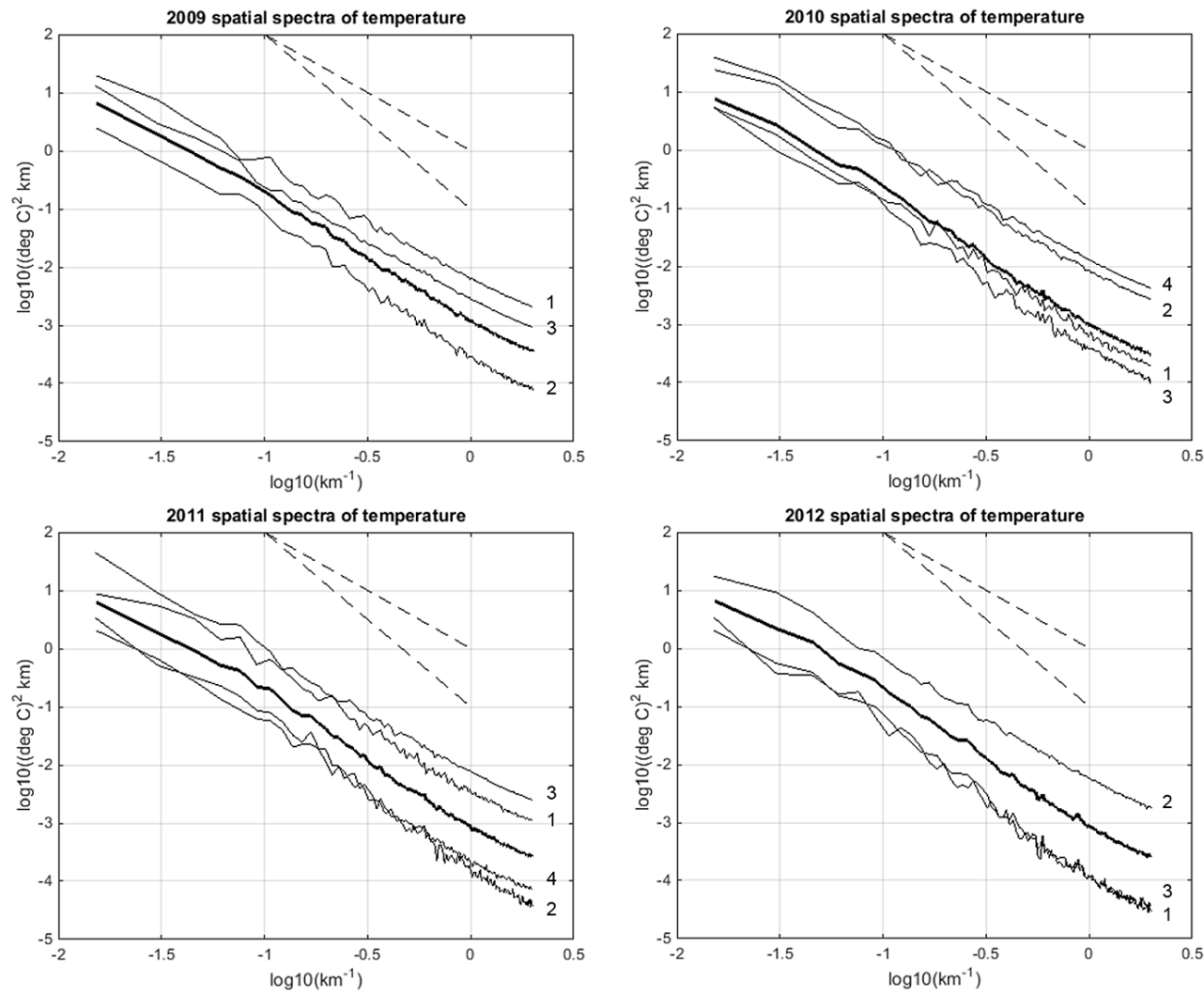

Figure 5. Horizontal wavenumber spectra of temperature variance in the surface layer of the Gulf of Finland calculated using Ferrybox data from the Tallinn-Helsinki ferry line in the summers of 2009-2012. The bold lines show the average spectral curve for the entire study period from 29 June to 31 August in each year, and the thin lines represent the average spectral curves in the selected periods. The numbers of the periods, corresponding to those marked in Fig. 4 and listed in Table 1, are shown close to each respective spectral curve. The dashed lines correspond to -2 and -3 slopes.

clearly larger separation between the spectral curves at the sub-mesoscale than at the mesoscale. While the spectral density of spatial variations of temperature at the spatial scale of $1 \mathrm{~km}$ varied more than 1.5 in magnitude, it varied in ranges of 1 magnitude at the spatial scale of $10 \mathrm{~km}$ (Fig. 5).

\subsection{Temporal variability of the vertical stratification}

The vertical distributions of temperature and salinity at the buoy station varied considerably in time similarly to the horizontal distributions of temperature and salinity along the ferry route. The variations were revealed as changes in the magnitude of vertical gradients, depth of the upper mixed layer and seasonal thermocline, fast deepening or surfacing of the thermocline, and occurrence of intrusions leading in certain cases to local inversions in vertical salinity distribution (Fig. 3).

Temporal changes in vertical stratification in the Gulf of Finland could be related to the differences in the heat flux through the sea surface and to the prevailing wind forcing that influences both the estuarine circulation alterations and the intensity of vertical mixing (see e.g., Liblik and Lips,
2012). Note that the autonomous buoy station in the present study was located in the southern part of the open Gulf of Finland. Thus, in addition to the seasonal course of stratification and its dependence on the estuarine circulation, the vertical stratification at this location could be significantly influenced both by the upwelling and by the downwelling along the southern coast.

Stratification parameter $(P)$ calculated for the water layer between the sea surface and $40 \mathrm{~m}$ depth increased in July 2010 and 2011 in accordance with the strengthening of the seasonal thermocline (Fig. 6). In July-August of these years, the winds from the southeast prevailed supporting the estuarine circulation and, in turn, keeping up the strong vertical stratification; the maximum of $P=370 \mathrm{~J} \mathrm{~m}^{-3}$ was observed at the beginning of August 2010. This continuous increase of $P$ in both years was disrupted only due to the coastal upwelling events (in 2010 also due to a weak downwelling event) leading to rapid changes in the stratification parameter mostly because of vertical movements of the thermocline. In contrast to 2010 and 2011, the stratification parameter did not increase much during the study window in 2009 and 2012 in accordance with the prevailing southwest- 

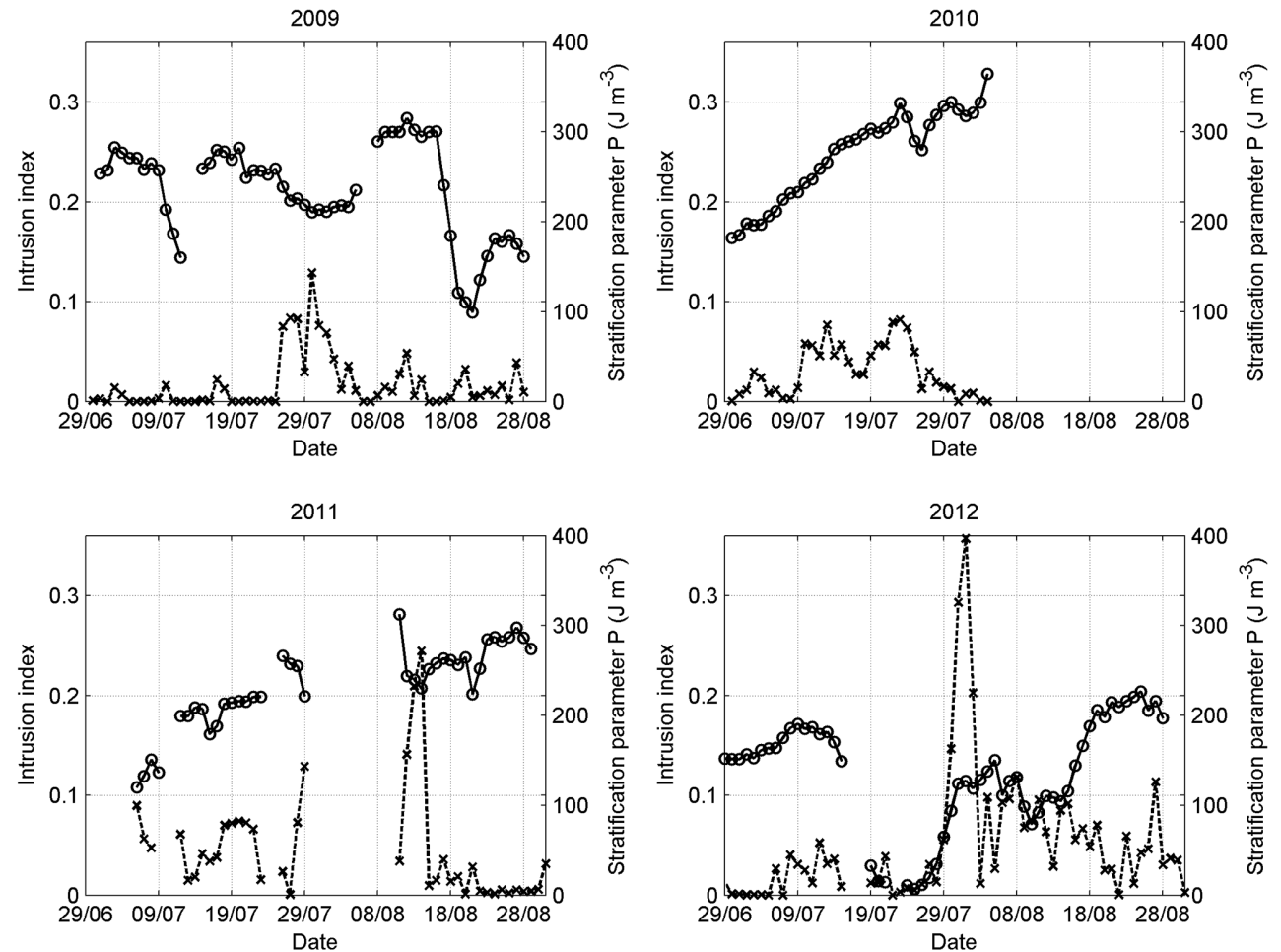

Figure 6. Daily average stratification parameter (solid line with open circles) and intrusion index (dashed line with crests) estimated for the water column from the sea surface to $40 \mathrm{~m}$ depth at the buoy station AP5 in the central Gulf of Finland from 29 June to 31 August in 2009-2012. Location of the buoy station is shown in Fig. 1.

erly winds. In 2009, the stratification parameter being relatively high due to the vertical salinity stratification had the maximum in the first half of August $\left(P=300 \mathrm{~J} \mathrm{~m}^{-3}\right)$ and decreased rapidly afterwards when the downwelling influence reached the buoy station. In 2012, the vertical stratification in the water layer from the surface to $40 \mathrm{~m}$ depth almost vanished at the measurement site AP5 by 20 July due to a very strong downwelling event, which appeared along the southern coast of the Gulf of Finland. Later on, the stratification at the buoy station strengthened, but the stratification parameter was clearly the lowest in 2012 if compared to the other years due to the deepest position of the seasonal thermocline.

Vertical profiles of temperature and salinity collected at the buoy station often exposed variability with vertical scales of a few to $10 \mathrm{~m}$, which could be interpreted as intrusions related to the sub-mesoscale dynamics. Since the temperature was the main contributor to the vertical density distribution in the seasonal thermocline, such intrusions could create local inversions in the vertical distribution of salinity as mentioned above and seen in Fig. 3. The calculated intrusion index showing how much the vertical stratification is weakened due to local salinity inversions varied mostly between 0 and 0.05 . However, every year one or a few periods were detected when the index exceeded 0.05 , whereas the maximum index value obtained on 1-2 August 2012 reached 0.36.
In 2009 , the only period with relatively high intrusion index values was detected during and just after the period of estuarine circulation reversal (Liblik and Lips, 2012). The maximum of the intrusion index coincided with the last day of the upwelling event near the northern coast that was followed by the event near the southern coast and rapid decrease of the intrusion index. In 2011, the index values $>0.05$ were detected a few times in July, whereas the highest values on 12-14 August (exceeding 0.24 on 14 August) were related to the relaxation of an intense upwelling event near the southern coast and short-term deepening of the thermocline at the buoy station during a weak upwelling event near the northern coast. The mentioned highest intrusion index value on 1-2 August 2012 was detected within the period when two consecutive major upwelling events occurred near the northern coast, whereas this maximum emerged between the upwelling events just before the second one.

Thus, the intrusions were most intense (in the sense of salinity inversions) at the buoy station AP5 in connection with the relaxation of upwelling events near the southern coast, development of upwelling events near the northern coast and estuarine circulation reversals. All these situations correspond to the periods when the thermocline was deepening or was already at a deep position at the buoy station in the southern part of the open Gulf of Finland. In addition, the stratification parameter values were low or decreas- 

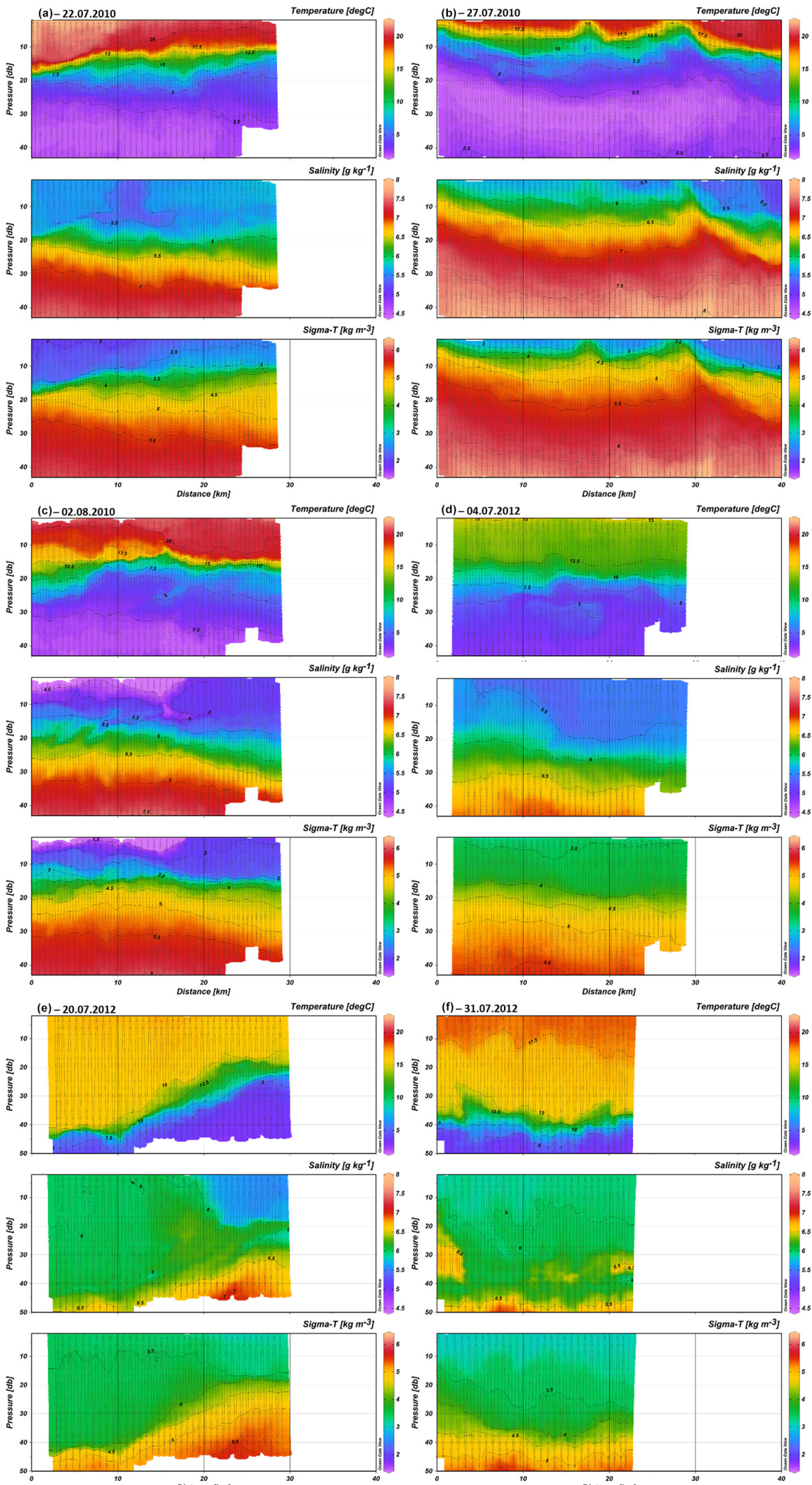

Figure 7. Vertical sections of temperature, salinity, and density anomaly measured using the ScanFish on 22 July 2010 (a), 27 July 2010 (b), 2 August 2010 (c), 4 July 2012 (d), 20 July 2012 (e), and 31 July 2012 (f). The corresponding ScanFish tracks are shown in Fig. 1. 

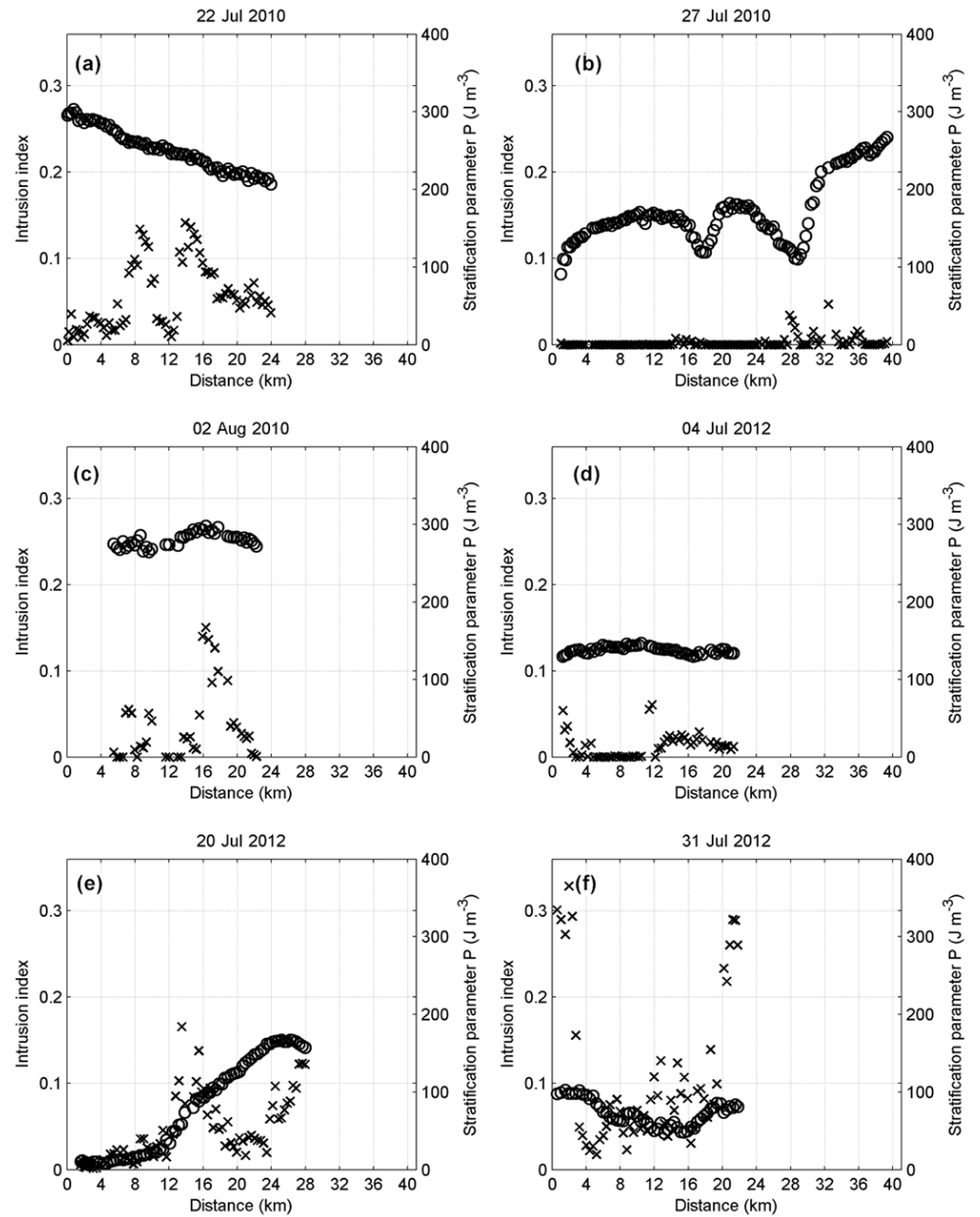

Figure 8. Stratification parameter (open circles) and intrusion index (crests) estimated for the water column from the sea surface to $40 \mathrm{~m}$ depth along the ScanFish tracks on 22 July 2010 (a), 27 July 2010 (b), 2 August 2010 (c), 4 July 2012 (d), 20 July 2012 (e), and 31 July 2012 (f). The corresponding ScanFish tracks are shown in Fig. 1.

ing when the temporal maximum of intrusion index was detected. When relating intrusion index values with the lateral variability in the surface layer one could conclude that the found temporal maxima of intrusion index corresponded to the periods of moderate lateral variability in the surface layer. Nevertheless, during such periods, the slopes of horizontal wavenumber spectra of temperature variance were close to -2 as during the periods of high lateral variability, and approximately a week before the highest intrusion index values, the lateral variability in the surface layer was also high (Figs. 4 and 6).

\subsection{Spatial variability in the thermocline}

We analyzed the data of ScanFish surveys in the Gulf of Finland conducted across the gulf in the open, deeper part and along the southern coast in the summers of 2010 and 2012. The hydrographic background of surveys in 2010 is characterized by the development of a weak upwelling along the northern coast of the gulf on 22 July 2010, a strong upwelling event along the southern coast on 27 July 2010 and relaxation of it by 2 August 2010 when the last survey was conducted (see Fig. 3c, d). In summer 2012, when the upwelling events along the northern coast dominated, the survey on 4 July 2012 characterizes the situation before those upwelling events, on 20 July 2012 the development of upwelling and on 31 July 2012, which was conducted along the gulf, the situation related to a temporal relaxation of upwelling (see Fig. 3g, h).

A clear cross-gulf inclination of the thermocline was revealed on 22 July 2010 (Fig. 7a), although the ScanFish section did not reach the upwelling area near the northern coast. At the same time, the isopycnals had opposite inclination below the $20 \mathrm{~m}$ depth resulting in a weakening of the vertical stratification from south to north (Fig. 8). A wellpronounced, less saline water zone with a width of less than $5 \mathrm{~km}$ was observed in the surface layer. The extension of an associated intrusion of lower salinity in the thermocline was 

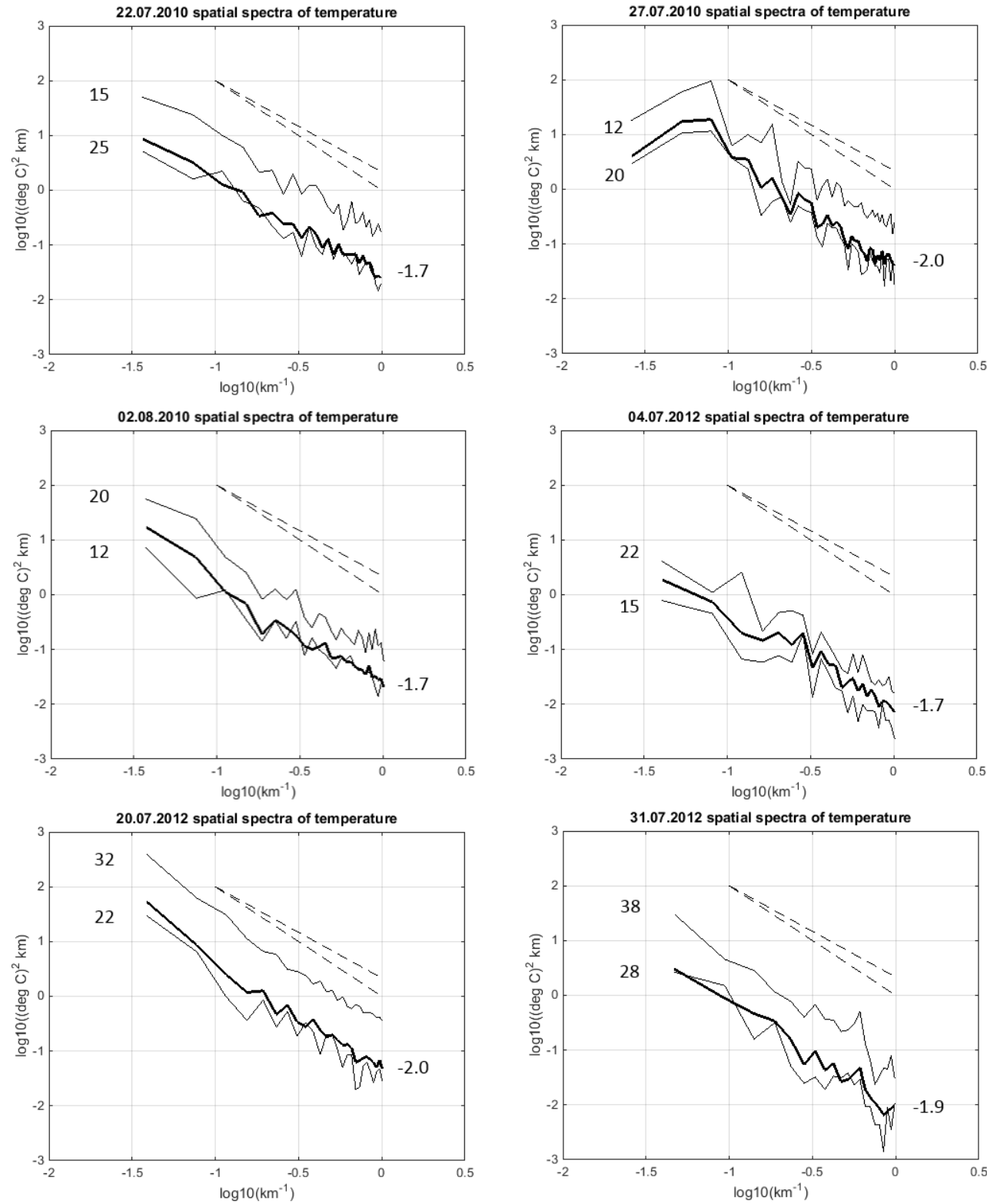

Figure 9. Horizontal wavenumber spectra of temperature variance in the sub-surface layer of the Gulf of Finland calculated using ScanFish data from 22 July 2010, 27 July 2010, 2 August 2010, 4 July 2012, 20 July 2012, and 31 July 2012. The bold lines show the average spectral curve for each survey and the thin lines represent the spectral curves in the selected layers with the thickness of $10 \mathrm{~m}$. The central depth values of the selected layers are indicated at the left side of panels and the estimated spectral slopes for the average spectral curve at the right of panels. The dashed lines correspond to $-5 / 3$ and -2 slopes.

wider in the horizontal dimension and its thickness, decreasing from north to south in accordance with the strength of the vertical stratification, was less than $5 \mathrm{~m}$.

The along-gulf ScanFish section on 27 July 2010 from the buoy station AP5 to the southwest crossed the meandering upwelling front (Fig. 7b). The observed variability is characterized by clear mesoscale meanders of the front with spatial scales of $10-15 \mathrm{~km}$, strong stratification at the warm, less saline side of the front and much weaker stratification at the cold, more saline side of it, and very low intrusion index almost along the entire section (Fig. 8b). A remarkable variability at the sub-mesoscale, also resulting in intrusions of water with different salinity seen in Fig. 7c and expressed in high values of intrusion index (Fig. 8c), was observed on 2 August 2010. A less saline water zone was well visible almost at the same location as on 22 July 2010, but the surface layer salinity in it was much lower, less than $4.5 \mathrm{~g} \mathrm{~kg}^{-1}$ (Fig. 7c). 

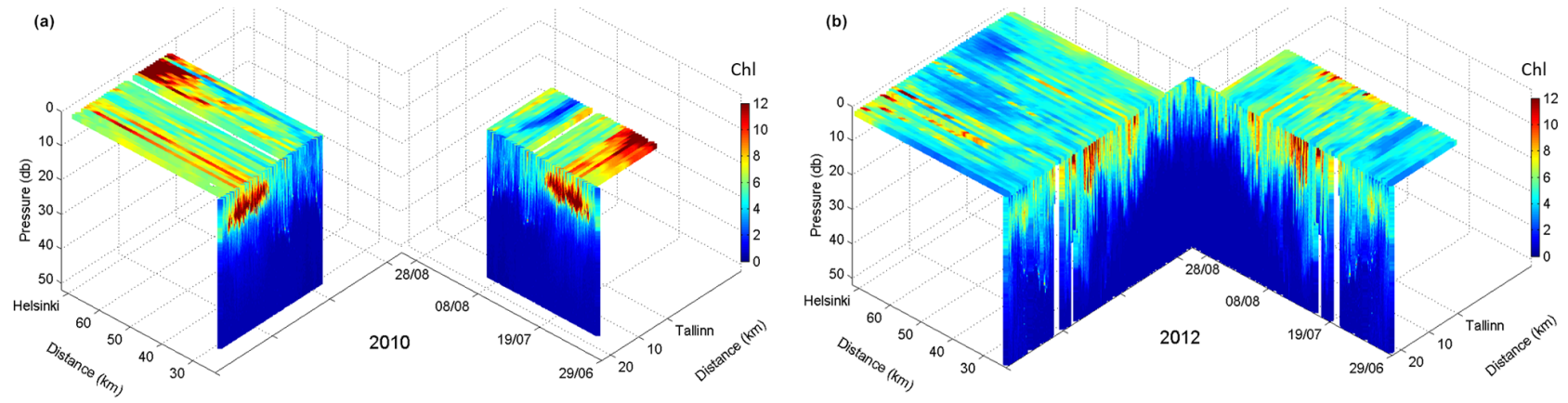

Figure 10. Temporal changes in horizontal and vertical distribution of chlorophyll $a\left(\mathrm{mg} \mathrm{m}^{-3}\right)$ in the Gulf of Finland measured by the Ferrybox system between Tallinn and Helsinki and the autonomous buoy profiler at station AP5 from 29 June to 31 August in 2010 (a) and 2012 (b). The Ferrybox route and the location of station AP5 are shown in Fig. 1.

Table 1. Standard deviations of temperature and slopes of wavenumber spectra of temperature variance based on the data collected in the surface layer along the ferry route between Tallinn and Helsinki. Average values for each year over the study period from 29 June to 31 August (to 22 August in 2012) and within the selected periods with similar spatial variability are given. Numbers of the periods correspond to the periods marked in Fig. 4.

\begin{tabular}{llrr}
\hline $\begin{array}{l}\text { Year } \\
\text { no. }\end{array}$ & Dates & $\begin{array}{r}\text { Standard } \\
\text { deviation } \\
\left({ }^{\circ} \mathrm{C}\right)\end{array}$ & $\begin{array}{r}\text { Spectral } \\
\text { slope } \\
(10-0.5 \mathrm{~km})\end{array}$ \\
\hline 2009 & 29 June-31 August & 0.71 & -2.1 \\
1 & 29 June-15 July & 1.26 & -1.9 \\
2 & 16 July-14 August & 0.37 & -2.3 \\
3 & 15 August-31 August & 0.78 & -1.9 \\
\hline 2010 & 29 June-31 August & 0.83 & -2.2 \\
1 & 29 June-18 July & 0.52 & -2.3 \\
2 & 19 July-31 July & 1.46 & -2.0 \\
3 & 1 August-16 August & 0.48 & -2.2 \\
4 & 17 August-24 August & 1.89 & -1.9 \\
\hline 2011 & 29 June-31 August & 0.73 & -2.2 \\
1 & 29 June-12 July & 0.93 & -2.1 \\
2 & 13 July-25 July & 0.38 & -2.6 \\
3 & 26 July-9 August & 1.43 & -1.9 \\
4 & 10 August-31 August & 0.34 & -2.2 \\
\hline 2012 & 29 June-22 August & 0.76 & -2.2 \\
1 & 29 June-16 July & 0.32 & -2.6 \\
2 & 17 July-13 August & 1.16 & -2.0 \\
3 & 14 August-22 August & 0.35 & -2.4 \\
\hline
\end{tabular}

The average vertical gradients of all parameters - temperature, salinity, and density - in the upper $40 \mathrm{~m}$ water layer were clearly lower in summer 2012 (Fig. 7d-f) than in summer 2010 (Fig. 7a-c). A less saline water zone in the central part and slightly stronger vertical stratification in the southern part of the section were observed on 4 July 2012 (Figs. 7d and $8 \mathrm{~d}$ ). Development of the upwelling along the northern coast and downwelling in the southern part caused strong inclination of the thermocline across the gulf and a clear strengthening of vertical stratification from south to north on 20 July 2012 (Figs. 7e and 8e). In the area of strong inclination of the thermocline, relatively large horizontal gradients of salinity and intense sub-mesoscale variability, also seen as intrusions of water with different salinity (Fig. 7e), were observed. On 31 July 2012, the ScanFish survey revealed a mesoscale eddy-like feature (Fig. 7f), which could be formed in the process of downwelling relaxation as also observed earlier along the southern coast of the gulf (in its mouth area; see Lips et al., 2005). This mesoscale feature was characterized by relatively weak vertical stratification in its central part and high intrusion index values, especially at its periphery (Fig. 8f). Note that the pronounced intrusion of more saline water detected at the western end of the section was also registered at the buoy station during several days (Fig. 3h).

The horizontal wavenumber spectra of temperature variance shown in Fig. 9 vary considerably between the analyzed six surveys, both in the spectral level and the shape of the curves. The highest variability at the meso- and submesoscale was related to the surveys, which were conducted when pronounced upwelling events dominated in the study area, on 27 July 2010 and 20 July 2012. The former survey crossed the meandering upwelling front, and the peak of the spectral density was found at the lateral scale of about $15 \mathrm{~km}$. The latter survey was conducted when an upwelling event along the northern coast was developing, and the ScanFish section crossed the inclined thermocline. A similar situation with a weaker upwelling development and slightly lower spectral densities was mapped on 22 July 2010.

The spectral slopes between the horizontal scales of 10 and $1 \mathrm{~km}$ for spectra averaged over depth intervals with the thickness of $10 \mathrm{~m}$ were mostly shallower than -2 ; the average values of spectral slopes for each survey (shown in Fig. 9) varied between -1.7 and -2.0 . The slopes close to -2 were obtained for the surveys with the most pronounced mesoscale features. Local vanishing of the spectral slope 

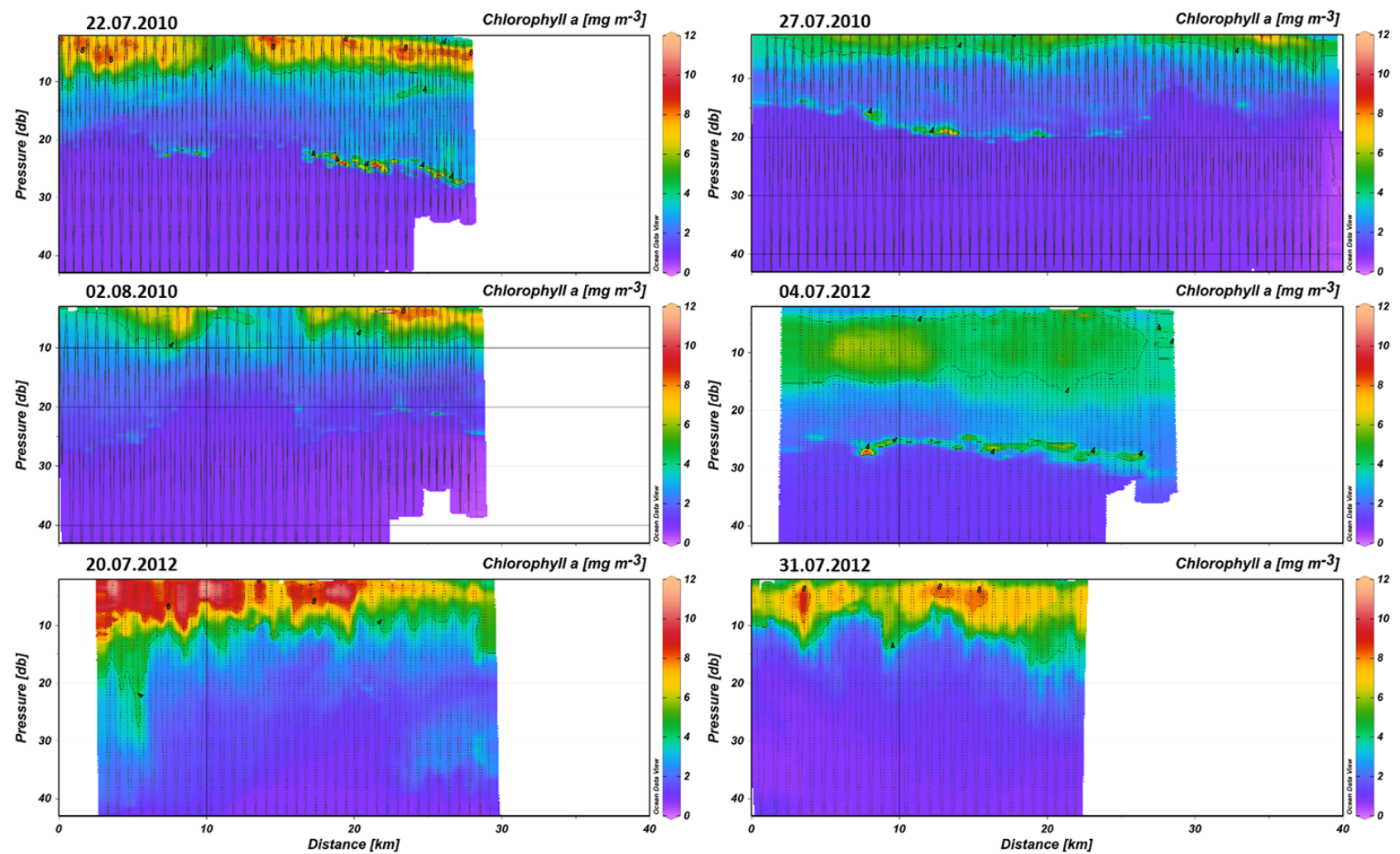

Figure 11. Vertical sections of chlorophyll $a$ content measured using the ScanFish on 22 July 2010, 27 July 2010, 2 August 2010, 4 July 2012, 20 July 2012, and 31 July 2012. The corresponding ScanFish tracks are shown in Fig. 1.

could be detected between the horizontal scales from 3 to $1 \mathrm{~km}$ on 2 August 2010 and at scales from 3 to $2 \mathrm{~km}$ on 31 July 2012. High intrusion index values were characteristic for the both mentioned surveys, especially for the survey on 31 July 2012 (Fig. 8c, f), which is in accordance with the index estimates based on the buoy profiler data (Fig. 6d). High intrusion index values were also found for the survey on 20 July 2012 when a patch of more saline water appeared in the sub-surface layer at the warm side of the upwelling front (Figs. 7d and 8d).

\subsection{Consequences to chlorophyll $a$ dynamics}

Temporal variability of chlorophyll $a$ at the scales of days is usually much higher than that of temperature and salinity since in addition to the advection and mixing, the phytoplankton growth (and decay) could increase (decrease) the biomass and consequently chlorophyll $a$ content rapidly. Despite such high variability and other factors that could influence the comparability of acquired chlorophyll $a$ fluorescence data, e.g., fluorescence quenching, the presented combined plots of changes in horizontal and vertical distributions agree reasonably well (Fig. 10).

In the first half of July 2010, a sub-surface bloom developed in the southern part of the Gulf of Finland, which occasionally was also seen in the surface layer with higher chlorophyll $a$ values off the southern coast (Fig. 10a). When an upwelling event along the southern coast started to dominate (see Fig. 3c), the chlorophyll $a$ content decreased in the southern part and increased in the northern part of the study area. Before the bloom near the northern coast, relatively deep chlorophyll $a$ maxima were detected at the buoy station at depths below $20 \mathrm{~m}$ (since the maxima layers were thin they are not well seen in Fig. 10) and at the ScanFish section on 22 July 2010, especially at its northern part (Fig. 11). When the upwelling developed along the southern coast of the gulf, the sub-surface chlorophyll $a$ maxima were situated at a shallower position in the warmer side of the front, but they almost disappeared by 2 August 2010 after relaxation of the upwelling event. In between the two surveys, the bloom developed near the northern coast in the convergence/downwelling area. It was suggested that this bloom could be related to the observed sub-surface maxima of chlorophyll $a$, which contained the dinoflagellate Heterocapsa triquetra in very high numbers (Lips and Lips, 2014).

In 2012, the chlorophyll $a$ content was higher in the northern half of the study area than in its southern part in the first half of July. Later, when the two consecutive upwelling events appeared along the northern coast, the highest chlorophyll $a$ values were observed close to the southern coast. At 
the buoy station, where the downwelling influence was visible (see Fig. 3g), the chlorophyll $a$ content also increased in the sub-surface layer. Occasionally, high chlorophyll $a$ values were detected close to the upwelling front in the northern part of the study area. While the sub-surface maxima of chlorophyll $a$ were observed at the buoy station and the ScanFish transect at the beginning of July 2012 (Fig. 11), they disappeared when the upwelling events occurred near the northern coast. During the upwelling development, both the chlorophyll $a$ content in the surface layer and the thickness of the surface layer with elevated chlorophyll $a$ increased from north to south. However, those tendencies had pronounced intermittency at lateral scales of 1 to a few kilometers. A similar distribution pattern was registered in the phase of the upwelling/downwelling relaxation on 31 July 2012.

\section{Discussion and conclusions}

Many earlier studies have noticed that proper in situ measurements to reveal sub-mesoscale features are difficult to organize since the variability both in space and in time has to be tackled simultaneously (e.g., Hosegood et al., 2008, Niewiadomska et al., 2008, Pietri et al., 2013). Especially challenging are the investigations of sub-mesoscale processes in the coastal, relatively shallow but vertically stratified sea areas where the characteristic baroclinic Rossby radius is on the order of a few kilometers, as in the Gulf of Finland $-2-5 \mathrm{~km}$ (Alenius et al., 2003). We suggest that the most promising approach to solve the problem is to apply a combination of autonomous and research-vessel-based devices, such as Ferryboxes, moored profilers, underwater autonomous vehicles (gliders) and towed undulating instruments (ScanFish).

Simultaneous temporal changes that could be related to mesoscale processes are clearly seen in horizontal and vertical distributions of temperature and salinity presented in Fig. 3. The sub-mesoscale features such as upwelling filaments were also registered simultaneously by both systems, for instance in the first half of July 2009 and on 24 July 2010. Furthermore, the buoy profiler and ScanFish simultaneously detected intrusions of water with different salinity in the thermocline layer. Thus, the application of high-resolution autonomous and towed devices, which measure horizontal and vertical distributions of environmental parameters, makes it possible to detect meso- and sub-mesoscale features and quantitatively estimate their properties. In the present study, the underwater gliders were not applied, but they have been successfully tested in the Baltic Sea (e.g., Karstensen et al., 2014).

If the high-resolution measurements have a large enough coverage in space and time, one is able to reveal statistical parameters of sub-mesoscale variability. In turn, this would lead to an improved parameterization of sub-grid processes in the numerical models that has been considered as a prob- lem in the modeling of the relatively shallow, but stratified Baltic Sea sub-basins (Tuomi et al., 2012; Omstedt et al., 2014). It also allowed us to display some general features of spatiotemporal variability of temperature and salinity in the study region - the central Gulf of Finland. The upwelling events along the southern coast were associated with higher horizontal variability of temperature in the surface layer than those along the northern coast (Kikas and Lips, 2015; Liblik and Lips, 2016). In the case of prevailing westerly winds, the seasonal thermocline has a deeper position and the vertical gradient of salinity is weaker than in the case of easterly winds (Liblik and Lips, 2012).

One of the questions addressed in the present study was whether the wavenumber spectra of temperature variance convert to -3 slope predicted by the theory of quasigeostrophic turbulence in the ocean interior (Charney, 1971) or rather to $-5 / 3$ slope predicted by the theory of surface quasi-geostrophic turbulence (Held et al., 1995). We found that the wavenumber spectra of temperature variance in the surface layer had slopes varying mostly between -1.8 and -3.7 estimated for the lateral scales from 10 to $0.5 \mathrm{~km}$. Nevertheless, when high variability at the mesoscale, i.e., pronounced mesoscale features, were observed, the spectral slopes were shallower than -2 . Similar tendency towards -2 slope was obtained for the wavenumber spectra of temperature variance in the thermocline layer between the spatial scales of 10 and $1 \mathrm{~km}$. These estimates were very stable over the 4 years of Ferrybox measurements and all ScanFish surveys analyzed in the present study.

Such conversion of wavenumber spectra of temperature variance to -2 slope has been identified earlier in other sea areas by high-resolution modeling (e.g., Capet et al., 2008) and in situ measurements (e.g., Hodges and Rudnick, 2006). Based on remote sensing altimeter data, it is shown that sea level wavenumber spectra also correspond well to the surface quasi-geostrophic theory (Le Traon et al., 2008). In a recent study, Kolodziejczyk et al. (2015) showed that if the surface density is analyzed then the -2 spectral slope is obtained in summer conditions when the salinity and temperature variations do not compensate each other (in north-eastern subtropical Atlantic Ocean). We have used temperature data to estimate potential energy wavenumber spectra assuming that mostly temperature determines the density in the upper layer (including the seasonal thermocline) in the Gulf of Finland in summer. It has to be noted that the wavenumber spectra of density variance corresponded to -2 slope as well when the spatial variability was dominated by coastal upwelling events. According to these findings, the sub-mesoscale processes have to be more energetic than suggested by the quasigeostrophic theory of turbulence in the ocean interior. Thus, the observed high lateral variability of temperature in the surface layer and associated -2 spectral slopes suggest a significant role of sub-mesoscale processes in vertical exchanges in the stratified Gulf of Finland and similar sea areas. 
The lateral variability of temperature in the sub-surface layer was the highest during the surveys when the upwelling events either off the southern or off the northern coast occurred (ScanFish sections on 27 July 2010 and 20 July 2012). Higher intrusion index values in the sub-surface layer were also found at the ScanFish sections in relation to the development and relaxation of coupled upwelling/downwelling events, except at the section crossing the meandering upwelling front on 27 July 2010. One could suggest that the intrusion index (counted as a sum of salinity inversions) indicates the presence of the layered flow structure and thus, the intensity of lateral mixing. When analyzing the characteristics of coastal upwelling, Kikas and Lips (2015) suggested that two types of upwelling events could be identified. During the event on 18-27 July 2012, no pronounced upwelling front was detected, rather a gradual decrease of the surface temperature from the open sea towards the coast with remarkable variability at the sub-mesoscale was observed. It was suggested that such upwelling events could develop when the wind forcing is weaker than required to generate an Ekman drift in the entire upper layer and consecutive surfacing of the thermocline.

The observed salinity intrusions at the ScanFish section on 20 July 2012 support the above suggestion by Kikas and Lips (2015). The seasonal thermocline was relatively deep in July 2012 and most probably, the observed salinity intrusions were formed as a response to the winds favorable for the upwelling near the northern coast. Consequently, in such conditions, the lateral mixing is enhanced as the transport of water with different characteristics upward and downward along the inclined isopycnals. In turn, it could result in enhanced vertical (diapycnal) mixing of water at laterally distant places from their origin. We suggest that sub-mesoscale dynamics and layered flow structure contribute significantly to the lateral and vertical mixing in the stratified sea areas under variable wind forcing.

The highest values of intrusion index were registered at the buoy station in late July - early August 2012 and at the ScanFish section on 31 July 2012 during the relaxation of the downwelling near the southern coast. Apart of this major sub-mesoscale structure, similar intrusions visible in the vertical salinity distribution at the buoy station were quite frequent in the summers of 2009-2012 in the seasonal thermocline layer, e.g., in late July-early August 2009, in midAugust 2011 and in July and August 2012 (Fig. 3). In addition, water with slightly lower salinity was occasionally seen at the buoy station in July 2010 and clear evidence is provided by the ScanFish surveys on 22 July 2010 and 2 August 2010 that such intrusions of low salinity water in the upper part of the seasonal thermocline originated from patches of lower surface salinity in the central gulf. At least on two occasions could we detect clear inclination of salinity intrusions in relation to the isopycnals - on 2 August 2010 in the southern part of the section and on 20 July 2012 in the central part of it. This finding is similar to the observations by Pietri et al. (2013) in the upwelling system off southern Peru, where they suggested that observed sub-mesoscale features could be the result of the stirring by the mesoscale circulation. Note that the sub-surface chlorophyll $a$ maxima registered in the northern part of the ScanFish section on 22 July 2010 were also inclined in relation to the isopycnals (see Fig. 11).

Two examples of bloom development in the near-coastal convergence zone were shown in the present study - in late July 2010 near the northern coast and in July and August 2012 near the southern coast (Fig. 10). Lips and Lips (2014) suggested that the bloom near the northern coast in 2010 could be related to the sub-surface maxima of chlorophyll $a$, which contained the vertically migrating dinoflagellate Heterocapsa triquetra in very high numbers. Similar development of the biomass peak with a relatively high share of this vertically migrating species in the surface layer was observed in the same area also in August 2006 (Lips and Lips, 2010). The highest biomass and chlorophyll $a$ content in that convergence zone was associated with the locally higher location of isopycnals, thus, with the stratified conditions in the surface layer, although in the downwelling area.

The ScanFish surveys conducted during the downwelling event and its relaxation at the end of July 2012 did not show high chlorophyll $a$ content in the sub-surface layer. However, the data both from the buoy station and from the ScanFish surveys registered clearly enhanced chlorophyll $a$ content in the surface layer with quite a large intermittency in the chlorophyll $a$ content and layer thickness with enhanced chlorophyll $a$ content (Figs. 10 and 11). Note that the blooms lasted relatively long time (about 10 days), and the highest biomass (chlorophyll $a$ content) was not observed near the mesoscale upwelling front where the largest vertical velocities could be expected (e.g., Thomas and Lee, 2005). Levy et al. (2012) showed that the sub-mesoscale processes have large-scale effect on phytoplankton growth in the ocean, which could be seen at larger scales and distant places. An improvement in the resolution of ocean circulation models has resulted in more energetic motions not only close to the large scale (or mesoscale) fronts but rather in the surface layer of the whole modeling domain (Capet et al., 2008; Levy et al., 2010).

We suggest that the maintenance of the bloom, which could not be explained by pure convergence due to the Ekman drift in the surface layer, must benefit from other processes feeding the surface layer with nutrients and/or biomass. The ageostrophic sub-mesoscale processes could be responsible for re-stratification of the surface layer, vertical transport and thus, also for growth enhancement (Levy et al., 2012). This conclusion supports the concept that the vertical exchanges related to the mesoscale processes (eddies) are enhanced due to the sub-mesoscale activity and not only in the vicinity but also far off the mesoscale features (Klein and Lapeyre, 2009).

The results of the present study can be concluded as follows. The analysis of high-resolution data from summers 
2009-2012 revealed pronounced sub-mesoscale features in the surface and subsurface layer, e.g., upwelling and downwelling filaments and intra-thermocline intrusions with spatial scales of a few kilometers (typical baroclinic Rossby radius in the Gulf of Finland is $2-5 \mathrm{~km}$ ). The horizontal wavenumber spectra of temperature variance estimated between the lateral scales of 10 and (1) $0.5 \mathrm{~km}$ had the slopes close to -2 both in the surface layer and in the seasonal thermocline. It shows that the ageostrophic sub-mesoscale processes contribute considerably to the energy cascade in this stratified sea basin. We showed that the role of submesoscale processes was significant especially in the conditions of changing wind forcing, e.g., during the development and relaxation of coastal upwelling and downwelling events. We suggest that the sub-mesoscale processes play a major role in feeding surface blooms in the conditions of coupled coastal upwelling and downwelling events in the Gulf of Finland.

Acknowledgements. The work was supported by institutional research funding (IUT19-6) of the Estonian Ministry of Education and Research, by the Estonian Science Foundation grant no. 9023 and by EU Regional Development Foundation, Environmental Conservation and Environmental Technology R\&D Programme project VeeOBS (3.2.0802.11-0043).

Edited by: H. Wehde

\section{References}

Aitsam, A., Hansen, H.-P., Elken, J., Kahru, M., Laanemets, J., Pajuste, M., Pavelson, J., and Talpsepp, L.: Physical and chemical variability of the Baltic Sea: a joint experiment in the Gotland basin, Cont. Shelf Res., 3, 291-310, 1984.

Alenius, P., Nekrasov, A., and Myrberg, K.: Variability of the baroclinic Rossby radius in the Gulf of Finland, Cont. Shelf Res., 23, 563-573, 2003

Bouffard, J., Renault, L., Ruiz, S. Pascual, A., Dufau, C., and Tintoré, J.: Sub-surface small-scale eddy dynamics from multisensor observations and modeling, Progr. Oceanogr., 106, 62-79, 2012.

Capet, X., Mcwilliams, J. C., Molemaker, M. J., and Shchepetkin, A. F.: Mesoscale to submesoscale transition in the California current system, Part I: Flow structure, eddy flux, and observational tests, J. Phys. Oceanogr., 38, 29-43, 2008.

Charney, J.: Geostrophic turbulence, J. Atmos. Sci., 28, 1087-1095, 1971.

HELCOM: Guidelines for the Baltic monitoring programme for the third stage, Part D: Biological determinants, Baltic Sea Environmental Proceedings, 27, 1-161, 1988.

Held, I. M., Pierrehumbert, R. T., Garner, S. T., and Swanson, K. L.: Surface quasi-geostrophic dynamics, J. Fluid Mech., 282, 1-20, 1995.

Hodges, B. A. and Rudnick, D. L.: Horizontal variability in chlorophyll flyuorescence and potential temperature, Deep-Sea Res. Pt. I, 53, 1460-1482, 2006.
Hosegood, P. J., Gregg, M. C., and Alford, M. H.: Restratification of the surface mixed layer with submesoscale lateral density gradients: diagnosing the importance of the horizontal dimension, $\mathrm{J}$. Phys. Oceanogr., 38, 2438-2460, 2008.

Jenkins, W. J.: Nitrate flux into the euphotic zone near Bermuda, Nature, 331, 521-523, 1988.

Karstensen, J., Liblik, T., Fischer, J., Bumke, K., and Krahmann, G.: Summer upwelling at the Boknis Eck time-series station (1982 to 2012) - a combined glider and wind data analysis, Biogeosciences, 11, 3603-3617, doi:10.5194/bg-11-3603-2014, 2014.

Kikas, V. and Lips, U.: Upwelling characteristics in the Gulf of Finland (Baltic Sea) as revealed by Ferrybox measurements in 2007-2013, Ocean Sci. Discuss., 12, 2863-2898, doi:10.5194/osd-12-2863-2015, 2015.

Klein, P. and Lapeyre, G.: The oceanic vertical pump induced by mesoscale and submesoscale turbulence, Annu. Rev. Mar. Sci., 1, 351-75, 2009.

Kolodziejczyk, N., Reverdin, G., Boutin, J., and Hernandez, O.: Observation of the surface horizontal thermohaline variability at mesoscale to submesoscale in the north-eastern subtropical Atlantic Ocean, J. Geophys. Res. Oceans, 120, 2588-2600, 2015.

Laanemets, J., Väli, G., Zhurbas, V., Elken, J., Lips, I., and Lips, U.: Simulation of mesoscale structures and nutrient transport during summer upwelling events in the Gulf of Finland in 2006, Boreal Environ. Res., 16, 15-26, 2011.

Le Traon, P. Y., Klein, P., Hua, B. L., and Dibarboure, G.: Do altimeter wavenumber spectra agree with the interior or surface quasigeostrophic theory?, J. Phys. Oceanogr., 38, 1137-1142, 2008.

Levy, M., Klein, P., Trequier, A. M., Iovino, D., Madec, G., Masson, S., and Takahashi, K.: Modifications of gyre circulation by submesoscale physics, Ocean Model., 34, 1-15, 2010.

Levy, M., Ferrari, R., Franks, P. J., Martin, A. P., and Riviere, P.: Bringing physics to life at the submesoscale, Geophys. Res. Lett., 39, L14602, doi:10.1029/2012GL052756, 2012.

Liblik, T. and Lips, U.: Variability of synoptic-scale quasistationary thermohaline stratification patterns in the Gulf of Finland in summer 2009, Ocean Sci., 8, 603-614, doi:10.5194/os-8603-2012, 2012

Liblik, T. and Lips, U.: Variability of pycnoclines in a three-layer, large estuary: the Gulf of Finland, Est. Boreal Environ. Res., in press, 2016.

Lips, I. and Lips, U.: Phytoplankton dynamics affected by the coastal upwelling events in the Gulf of Finland in July-August 2006, J. Plankton Res., 32, 1269-1282, 2010.

Lips, I., Lips, U., Jaanus, A., and Kononen, K.: The effect of hydrodynamics on the phytoplankton primary production and species composition at the entrance to the Gulf of Finland (Baltic Sea) in July 1996, Proc. Est. Acad. Sci. Biol. Ecol., 54, 210-229, 2005.

Lips, I., Lips, U., and Liblik, T.: Consequences of coastal upwelling events on physical and chemical patterns in the central Gulf of Finland (Baltic Sea), Cont. Shelf Res., 29, 1836-1847, 2009.

Lips, U. and Lips, I.: Bimodal distribution patterns of motile phytoplankton in relation to physical processes and stratification (Gulf of Finland, Baltic Sea), Deep-Sea Res. Pt. II, 101, 107-119, 2014

Lips, U., Lips, I., Liblik, T., Kikas, V., Altoja, K., Buhhalko, N., and Rünk, N.: Vertical dynamics of summer phytoplankton in a stratified estuary (Gulf of Finland, Baltic Sea), Ocean Dyn., 61, 903-915, 2011. 
Martin, A. P. and Pondaven, P.: On estimates for the vertical nitrate flux due to eddy pumping, J. Geophys. Res., 108, 3359, doi:10.1029/2003JC001841, 2003.

McGillicuddy, D. J., Robinson, A. R., Siegel, D. A., Jannasch, H. W., Johnson, R., Dickey, T. D., McNeil, J., Michaels, A. F., and Knap, A. H.: Influence of mesoscale eddies on new production in the Sargasso Sea, Nature, 394, 263-266, 1998.

Nausch, M., Nausch, G., Lass, H. U., Mohrholz, V., Nagel, K., Siegel, H., and Wasmund, N.: Phosphorus input by upwelling in the eastern Gotland Basin (Baltic Sea) in summer and its effects on filamentous cyanobacteria, Estuar. Coast. Shelf Sci., 83, 434-442, 2009.

Niewiadomska, K., Claustre, H., Prieur, L., and d'Ortenzio, F.: Submesoscale physical-biogeochemical coupling across the Ligurian Current (northwestern Mediterranean) using a bio-optical glider, Limnol. Oceanogr., 53, 2210-2225, 2008.

Omstedt, A., Elken, J., Lehmann, A., and Piechura, J.: Knowledge of the Baltic Sea physics gained during the BALTEX and related programmes, Progr. Oceanogr., 63, 1-28, 2004.

Omstedt, A., Elken, J., Lehmann, A., Leppäranta, M., Meier H. E. M., Myrberg, K., and Rutgersson, A.: Progress in physical oceanography of the Baltic Sea during the 2003-2014 period, Progr. Oceanogr., 128, 139-171, 2014.

Pietri, A., Testor, P., Echevin, V., Chaigneau, A., Mortier, L., Eldin, G., and Grados, C.: Fine scale vertical structure of the upwelling system of Southern Peru as observed from glider data, J. Phys. Oceanogr., 43, 631-646, 2013.
Simpson, J. H. and Bowers D. G.: Models of stratification and frontal movements in shelf seas, Deep-Sea Res., 28, 727-738, 1981.

Simpson, J. H., Brown, J., Matthews, J., and Allen, G.: Tidal straining, density currents and mixing in the control of estuarine stratification, Estuar. Coast., 13, 125-132, 1990.

Thomas, L. N.: Formation of intrathermocline eddies at ocean fronts by wind-driven destruction of potential vorticity, Dynam. Atmos. Oceans, 45, 252-273, 2008.

Thomas, L. N. and Lee, C. M.: Intensification of ocean fronts by down-front winds, J. Phys. Oceanogr., 35, 1086-1102, 2005.

Tuomi, L., Myrberg, K., and Lehmann, A.: The performance of the parameterisations of vertical turbulence in the $3 \mathrm{D}$ modelling of hydrodynamics in the Baltic Sea, Cont. Shelf Res., 50/51, 64-79, 2012.

Uiboupin R. and Laanemets J.: Upwelling characteristics derived from satellite sea surface temperature data in the Gulf of Finland, Baltic Sea, Boreal Environ. Res., 14, 297-304, 2009.

Uiboupin, R., Laanemets, J., Sipelgas, L., Raag, L., Lips, I., and Buhhalko, N.: Monitoring the effect of upwelling on the chlorophyll a distribution in the Gulf of Finland (Baltic Sea) using remote sensing and in situ data, Oceanologia, 54, 395-419, 2012. 